\title{
Blocking primers to enhance PCR amplification of rare sequences in mixed samples - a case study on prey DNA in Antarctic krill stomachs
}

\author{
Hege Vestheim*1 and Simon N Jarman ${ }^{2}$
}

Address: ${ }^{1}$ Department of Biology, University of Oslo, P.O. Box 1066, Blindern, 0316, Oslo, Norway and ${ }^{2}$ Australian Antarctic Division, 203 Channel Highway, Kingston, TAS, 7050, Australia

Email: Hege Vestheim* - h.f.vestheim@bio.uio.no; Simon N Jarman - simon.jarman@aad.gov.au

* Corresponding author

Published: 20 July 2008

Frontiers in Zoology 2008, 5:12 doi:10.1186/1742-9994-5-12
Received: 6 March 2008

Accepted: 20 July 2008

This article is available from: http://www.frontiersinzoology.com/content/5/1/12

(C) 2008 Vestheim and Jarman; licensee BioMed Central Ltd.

This is an Open Access article distributed under the terms of the Creative Commons Attribution License (http://creativecommons.org/licenses/by/2.0), which permits unrestricted use, distribution, and reproduction in any medium, provided the original work is properly cited.

\begin{abstract}
Background: Identification of DNA sequence diversity is a powerful means for assessing the species present in environmental samples. The most common molecular strategies for estimating taxonomic composition depend upon PCR with universal primers that amplify an orthologous DNA region from a range of species. The diversity of sequences within a sample that can be detected by universal primers is often compromised by high concentrations of some DNA templates. If the DNA within the sample contains a small number of sequences in relatively high concentrations, then less concentrated sequences are often not amplified because the PCR favours the dominant DNA types. This is a particular problem in molecular diet studies, where predator DNA is often present in great excess of food-derived DNA.
\end{abstract}

Results: We have developed a strategy where a universal PCR simultaneously amplifies DNA from food items present in DNA purified from stomach samples, while the predator's own DNA is blocked from amplification by the addition of a modified predator-specific blocking primer. Three different types of modified primers were tested out; one annealing inhibiting primer overlapping with the $3^{\prime}$ end of one of the universal primers, another annealing inhibiting primer also having an internal modification of five $\mathrm{dl}$ molecules making it a dual priming oligo, and a third elongation arrest primer located between the two universal primers. All blocking primers were modified with a $\mathrm{C} 3$ spacer. In artificial PCR mixtures, annealing inhibiting primers proved to be the most efficient ones and this method reduced predator amplicons to undetectable levels even when predator template was present in 1000 fold excess of the prey template. The prey template then showed strong PCR amplification where none was detectable without the addition of blocking primer. Our method was applied to identifying the winter food of one of the most abundant animals in the world, the Antarctic krill, Euphausia superba. Dietary item DNA was PCR amplified from a range of species in krill stomachs for which we had no prior sequence knowledge.

Conclusion: We present a simple, robust and cheap method that is easily adaptable to many situations where a rare DNA template is to be PCR amplified in the presence of a higher concentration template with identical PCR primer binding sites. 


\section{Background}

Euphausia superba is the dominant krill species in the Antarctic and a key component of the Southern Ocean ecosystem [e.g. [1]]. The population of Antarctic krill in the Scotia Sea alone is estimated to be 208 million tonnes [2] and the krill fishery has the potential to become the world's largest fishery [3]. It has long been recognized that Euphausia superba feeds primarily as a herbivore during the phytoplankton-rich periods of spring and summer, at least during daytime [e.g. [4], although heterotrophic food items are also known to be consumed [5]]. However, there is uncertainty about how adult Antarctic krill survive the winter. A variety of strategies have been proposed since krill do not seem to build up large fat reserves. These strategies include shrinkage [e.g. [6,7]], lowered metabolic rates $[8,9]$, switching to omnivory [10] or feeding on ice associated biota [e.g. [11]].

Krill diet is difficult to fully characterise because they feed on a very wide taxonomic range of prey items. The diversity of prey consumed by krill means that many dietary analysis methods will produce biased results because of the difference in detectability of different prey items. As a result of this, a number of methods for analysing krill diet have been tried.

DNA-based methods are perhaps the most promising ones and are now established as powerful tools for studying food chains [12]. Their advantage lies in enabling identification of prey when the remains are degraded or lack hard parts. As species-specific DNA sequences are moderately easy to identify, these methods are also generally better at making species-level identifications than other biomarker methods such as stable isotopes, signature lipids and antigen detection [13]. However, the predominance of one DNA template within a single sample can bias or restrict molecular analysis [14,15]. This is often the case in diet studies since prey DNA in stomachand faecal samples tend to be far more degraded than predator DNA. The extent of this overabundance of amplifiable predator DNA increases with the size of the target fragment $[16,17]$.

PCR (polymerase chain reaction)-based methods using universal primers will not be sensitive enough to detect low-abundance sequences since rare prey templates have a tendency for being missed in the early stages of the PCR. The universal primers which are conserved among the target prey species usually also amplify DNA from the predator by necessity, and hence prey-DNA is masked by predator-DNA $[18,19]$. Several approaches have therefore been applied in order to avoid only detecting the predator-DNA.
One of these methods is to remove predator DNA after PCR amplification by restriction enzymes [e.g. [20,21]; Figure 1]. But this method requires a unique cutting site in the predator sequence, which is often difficult to find. Furthermore, it will not work if the PCR has failed to amplify prey DNA because the predator DNA has dominated the PCR totally. A method (the SuPER-method) to cut only target DNA in a mix prior to PCR has been applied by Green and Minz [15] investigating microbial diversity, but this method still requires several extra handling steps and has apparently not achieved wide acceptance.

Another common method is to design species specific primers or probes for the detection of prey species of interest [e.g. [22-24]; Figure 1]. This approach is however not suitable if the potential range of prey species is large (given the need to design perhaps hundreds of probes) or unknown (making it impossible to design prey specific probes a priori). This is clearly the case with krill diet. It is also possible to design group specific primers targeting broader groups of potential prey, but not the predator [e.g. [25]]. This approach has previously been applied to studying the diatom component of Antarctic krill diet [26]. However, developing group-specific primers is problematic if they are designed for groups where complete sequence coverage is not available. In such situations the group specific primers might screen away not only predator DNA but also DNA from prey species of interest.

One way to avoid only detecting predator DNA, and at the same time ensuring that no potential prey is screened away, is to use universal PCR primers accompanied by a method that specifically blocks predator DNA from amplification.

"PCR-clamping" where peptide nucleic acids (PNAs), locked nucleic acids (LNAs), or morpholinos are used to suppress PCR amplification of wild-type or dominant sequences is one such method [see [27] for a recent review]. PNA/DNA duplexes for example have a higher melting temperature compared with DNA/DNA duplexes [28] and do not prime DNA polymerisation [29]. Hence, a sequence-specific PNA probe overlapping one of the PCR-primer attachment sites within the target sequence of interest will not work as a primer. This method has been widely applied to minimize amplification of the dominant sequence in the fields of clinical chemistry [e.g. [30]], environmental microbiology [e.g. [31]], parasitology [32], and to detect genetically modified organism content in food [33], but not to our knowledge in diet studies. However, synthesis time for clamping probes is several weeks and these probes are also quite expensive.

A simpler method compared to PCR-clamping is to use a predator specific blocking primer (i.e. a DNA oligo that 


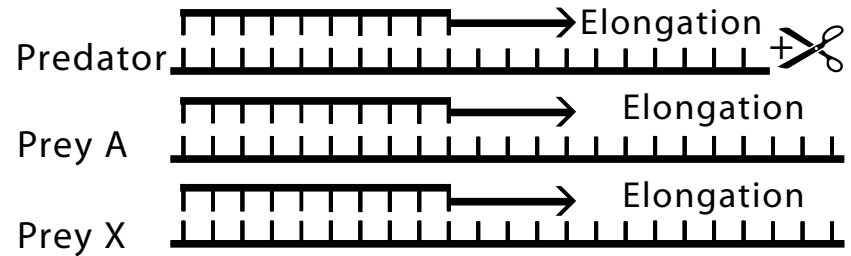

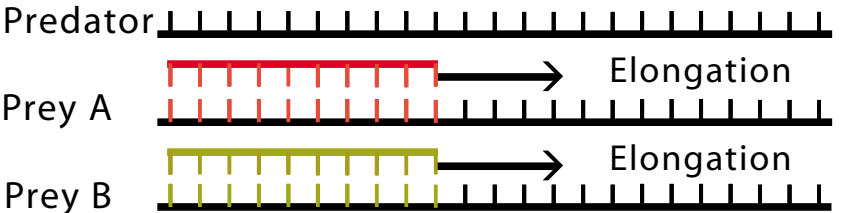

1. Universal primers amplifying target and non-target DNA. Removal of non-target DNA prior or after PCR with restriction enzymes. Requires unique cutting site in non-target sequence.

2. Species-specific PCR primers amplifying only target-DNA. Requires knowledge of all target sequences, and preferentially not too many different targets.

3. Group-specific PCR primers amplifying groups excluding non-target sequence. Difficult if non-target is closely related to targets or if complete sequence coverage of targets is unavailable.

4. Blocking non-target amplification, only target sequences amplified using universal PCR primers. The blocker can be a modified DNA oligonucleotide that does not prime amplification, or a clamping probe.

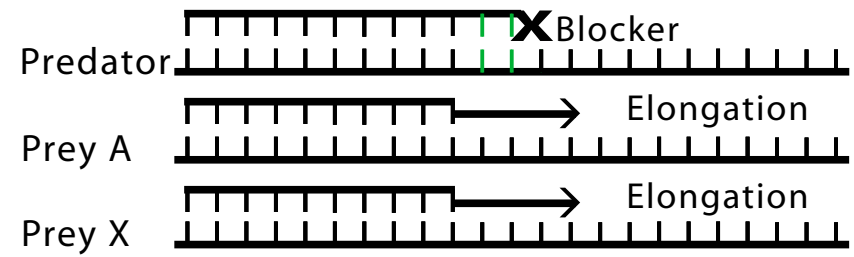

a) Annealing inhibiting blocker

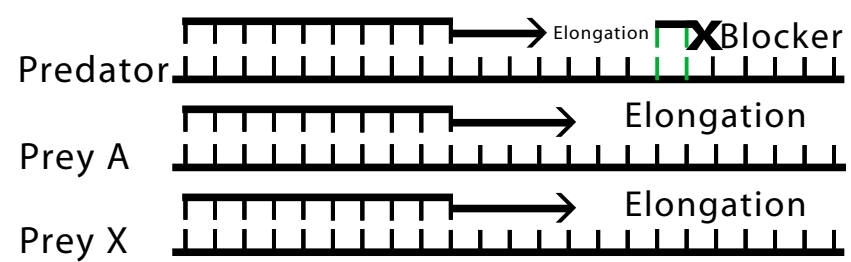

b) Elongation arrest blocker

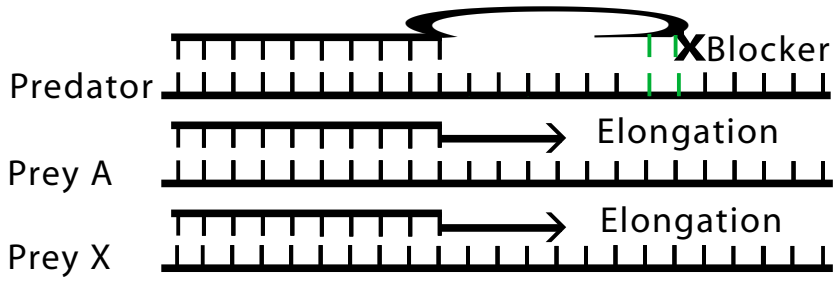

c) Annealing inhibiting DPO blocking primer

\section{Figure I}

Screening methods. Schematic illustration of different ways to screen away a dominating DNA template in a PCR mixture. I. Universal primers amplifying target and non-target DNA and removal of non-target DNA prior or after PCR with restriction enzymes. 2. Species-specific PCR primers amplifying only target-DNA. 3. Group-specific PCR primers amplifying groups excluding non-target sequence. 4. Blocking non-target amplification, only target sequences amplified using universal PCR primers a) annealing inhibiting blocking primer, b) elongation arrest blocking primer c) annealing inhibiting DPO blocking primer.

binds to predator DNA by preference but is modified so that it does not prime amplification) (Figure 1). This primer can compete with universal primers in a mix and block predator DNA amplification. Blocking primers have also been demonstrated to be useful in clinical research [e.g. [34]] and environmental microbiology studies, 
reducing amplification of a bacterial sequence that otherwise would have dominated the clone library [35]. In this study we test the application of blocking primers in diet studies and apply the method to assessing the diet of Antarctic krill caught during the austral autumn and winter.

\section{Methods}

Primer design

Primers applied in analysing of gut content of predators should ideally target short sequences of multiple-copy DNA because of the degraded nature of the prey derived sequences $[13,16,17,36]$. The ribosomal DNA is therefore often used as a target for PCR amplification in diet studies because ribosomal DNA (rDNA) genes are repeated tandemly in high copy numbers and are highly conserved within species [37]. We designed 'universal' PCR primers that amplify a short, but fairly variable region of the $28 \mathrm{~S}$ rDNA from all eukaryotes tested. We also designed three blocking primers intended to bind to the Euphausia superba sequence amplified by the universal primers. The primers used in this study are given in Table 1 and shown aligned with the krill sequence in Figure 2.

The blocking primer, 'Short28SR-blkKrill3'c3' overlapped with the $3^{\prime}$ end of the reverse universal primer, but extended into krill-specific sequence and was modified with a C3 spacer at the 3'-end (Figure 2). We needed a modification which was $100 \%$ synthesized (i.e. no oligos missing it) and which was stable (i.e. no degradation or enzymatic removing of the modification after synthesis). Even if just a small percentage of the blocking primers were to prime amplification of predator DNA as a result of not having the 3 modification, this would render the procedure unworkable. C3 spacer (3 hydrocarbons) CPG is a standard primer modification available from most suppliers of custom oligonucleotides. Adding this modification to the 3'-end of an oligonucleotide prevents elongation during a PCR without noticeably influencing its annealing properties. Because oligos are synthesized from a $3^{\prime}$ to $5^{\prime}$ direction, all molecules will be modified with the 3 ' modification. Modifying the 3'- end with a phosphate group (as chosen by Liles et al. [35]), a phosphate ester, or using an inverted 3'-3' linkage would also prevent elongation. However, side reactions during deprotection of the oligonucleotide or enzymatic impurities may free the 3'hydroxyl group to a small extent, and these methods are not so effective in blocking as C3 spacers CPG $[38,39]$.

Because finding an appropriate binding site for a species specific primer next to a binding site of a universal primer is often difficult, a krill specific blocking primer, Short28SF-DPO-blkKrill overlapping with the 3 'end of the forward universal primer and having an internal modification of five deoxyinosine ( $\mathrm{dI}$ ) molecules in addition to the $\mathrm{C} 3$ spacer modification was also designed (Figure 2 ). Very long conventional oligonucleotides often do not work. In general, primers longer than 25 bases are rarely used since their Tms can be over $70^{\circ} \mathrm{C}$, which is too high for effective PCR cycling [40]. Long primers also often generate many non-specific bands resulting from nonspecific annealing. A dual priming oligonucleotide (DPO) [41] contains two separate priming regions joined by a polydeoxyinosine linker. DPOs does not suffer from the limitations of a high Tm since the linker assumes a bubble-like structure resulting in two primer segments with distinct annealing properties. Furthermore, the bubblelike structure of linker efficiently prevents primer-dimer and hairpin structure formation [41].

The Short28SR-blkKrill3'c3 and the Short28SF-DPOblkKrill blocking primers were both designed to prevent annealing of the unmodified version of the universal primer on krill sequences. Further a third krill specific blocking primer situated between the two universal primers was tested (Figure 2). This was an "elongation arrest" primer ([42]; Figure 1) and also had a C3 spacer at its 3' end.

\section{Sampling and DNA extraction}

Total genomic DNA was extracted from ethanol-preserved specimens of Antarctic pelagic invertebrates or cultured algal species (Table 2).

Table I: 28S PCR primers used in this study.

\begin{tabular}{|c|c|}
\hline Primer name & Sequence $\left(5^{\prime} \rightarrow 3^{\prime}\right)$ \\
\hline Short28SF & GTGTAACAACTCACCTGCCG \\
\hline Short28SR & GCTACTACCACCAAGATCTG \\
\hline Short28SseqF & AGCAGGACGGTGGYCATGGAAGTCG \\
\hline Short28SseqR & GCACTGGGCAGAAATCACATTGCG \\
\hline 28S-EIArKrill-3'c3 & GTTGGGGCAGTAACGGCCCTTGCGGG3 \\
\hline Short28SR-blkKrill-3'c3 & CCACCAAGATCTGCACTAGCGGCGG3 \\
\hline Short28SF-DPO-blkKrill & $\begin{array}{l}\text { CCTGCCGAAGCAACTAGCCCTGAAAATGGATG } \\
\text { GCGCTCAAGCGTCCTC44444ACTCGACCGTTG3 }\end{array}$ \\
\hline
\end{tabular}

$4=$ dlnosine; $3=$ C3spacer 
Figure 2

Primers. A 203 bp region of Euphausia superba 28S sequence showing the location of the different primers applied in this study.

Krill were collected during two cruises in eastern Antarctic waters with RSV Aurora Australis. The first cruise took place during the austral autumn and the second in late austral winter (Table 2). Krill were collected using Rectangular Midwater Trawl- 8 net by standard double oblique tows from the surface down to $200 \mathrm{~m}$ or by target towing at aimed depths of $100 \mathrm{~m}$ or 16-60 m (Table 2). The vessel speed during net towing was maintained at 2 knots. Immediately after capture, krill were put into jars containing $80 \%$ ethanol as recommended by Passmore et al. [26].
After 1-6 months storage krill stomachs (foreguts) of ethanol rinsed krill were dissected under a dissecting microscope in sterile Petri dishes using flame sterilized forceps. Care was taken so the stomach was not in contact with any outer parts of the krill's exoskeleton. The stomach was then briefly rinsed in fresh ethanol and put into an autoclaved DNA free Eppendorf tube filled with ATL buffer (Qiagen). The sample was homogenized using a sterile plastic pestle prior to DNA extraction.

Table 2: List of species used for DNA analysis in this study with sampling site and GenBank accession numbers.

\begin{tabular}{|c|c|c|c|c|c|c|}
\hline Species & $\begin{array}{l}\text { Location/ } \\
\text { Cruise }\end{array}$ & Position & Date & $\begin{array}{l}\text { Time start } \\
\text { (and stop) } \\
\text { (UTC) }\end{array}$ & & $\begin{array}{l}\text { GenBank accession } \\
\text { number }\end{array}$ \\
\hline \multicolumn{7}{|l|}{ Algae } \\
\hline Pyramimonas sp. & $\begin{array}{l}\text { Ace Lake, } \\
\text { Vestfold } \\
\text { Hills }\end{array}$ & $68^{\circ} 28^{\prime} 18.5$ & $S 78^{\circ} 1 I^{\prime} 16 . I^{\prime \prime} \mathrm{E}$ & & & EU375499 \\
\hline \multicolumn{7}{|l|}{ Chaetognatha } \\
\hline Sagitta gazellae & SIPEX & $6503.81 \mathrm{~S}, 11941.91 \mathrm{E}$ & 29/09/2007 & $11: 10$ & & EU375500 \\
\hline \multicolumn{7}{|l|}{ Copepoda } \\
\hline $\begin{array}{l}\text { Calanus } \\
\text { propinquus }\end{array}$ & SIPEX & $6413.94 \mathrm{~S} I 1633.86 \mathrm{E}$ & $08 / 10 / 2007$ & $6: 46$ & & EU37550I \\
\hline $\begin{array}{l}\text { Euchirella } \\
\text { rostromagna }\end{array}$ & SIPEX & $6503.81 \mathrm{~S}, 11941.91 \mathrm{E}$ & $29 / 09 / 2007$ & & & EU375502 \\
\hline $\begin{array}{l}\text { Metridia } \\
\text { gerlachei }\end{array}$ & SIPEX & 6454.72 I S I77 I376 E & $05 / 10 / 2007$ & $13: 14$ & & EU375503 \\
\hline $\begin{array}{l}\text { Pareuchaeta } \\
\text { pseudotonsa }\end{array}$ & SIPEX & $6503.81 \mathrm{~S}, 11941.91 \mathrm{E}$ & 29/09/2007 & & & EU375504 \\
\hline \multicolumn{7}{|l|}{ Amphipoda } \\
\hline $\begin{array}{l}\text { Primno } \\
\text { macropa }\end{array}$ & SIPEX & $6503.81 \mathrm{~S}, 11941.91 \mathrm{E}$ & $29 / 09 / 2007$ & $11: 10$ & & EU375505 \\
\hline $\begin{array}{l}\text { Themisto } \\
\text { gaudichaudi }\end{array}$ & SIPEX & $6503.81 \mathrm{~S}, 11941.91 \mathrm{E}$ & $29 / 09 / 2007$ & $11: 10$ & & EU375506 \\
\hline \multicolumn{7}{|l|}{ Krill stomachs } \\
\hline & V4 06/07 & $660427 \mathrm{~S}, 1095895 \mathrm{E}$ & $24 / 03 / 2007$ & 08:5I-08:56 & $0-100 \mathrm{~m}$ & EU378965-EU379000 \\
\hline & SIPEX & 6518622 S, $12537353 \mathrm{E}$ & $17 / 09 / 2007$ & $12: 00$ & $16-60 \mathrm{~m}$ & \\
\hline & SIPEX & $6528046 \mathrm{~S}, 12039926 \mathrm{E}$ & 20/09/2007 & $12: 37-12: 57$ & $0-200 \mathrm{~m}$ & \\
\hline
\end{tabular}


All DNA was extracted with a DNeasy Blood \& Tissue kit (Qiagen) following the manufacturer's instruction for animal tissue and total DNA yield and quality of final extractions $(100 \mu \mathrm{L})$ was determined using Picofluor 8000-004 (Turner Designs) and samples stained with Quant-iT PicoGreen ds DNA reagent (Molecular Probes).

\section{Testing of blocking primers}

To evaluate the efficiency of the different types and different amounts of blocking primers, artificial rDNA mixtures were created. First PCR amplification were performed on krill and Pyramimonas DNA with the universal 28S rDNA primers Short28SF and Short28SR (Table 1) as $25 \mu \mathrm{L}$ reactions with $0.25 \mu \mathrm{L}$ of each oligo $(10 \mu \mathrm{M}), 0.25 \mu \mathrm{L} \mathrm{dNTP}$,

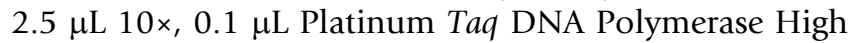
Fidelity (Invitrogen) $5 \mathrm{U} \cdot \mu^{-1}, 1 \mu \mathrm{L} \mathrm{Mg}^{2+}$ and $5 \mu \mathrm{L}$ DNA ( 10 ng $\left.\mu \mathrm{L}^{-1}\right)$.

The PCR products were then cloned using the TOPO TA Cloning system competent cells (Invitrogen). Transformants were screened using blue/white selection on LB-agar containing X-Gal and $10 \mathrm{mg} \cdot \mathrm{mL}^{-1}$ ampicillin or kanamycin. White or light blue colonies were picked for plasmid isolation, reincubated overnight in LB medium containing antibiotics and plasmids were then extracted using the Ultraclean miniplasmid extraction kit (Mo Bio, Carlsbad, CA, USA). Plasmids were linearized using HindIII restriction enzyme and the yield quantified using Picofluor 8000-004 (Turner Designs) and samples stained with Quant-iT PicoGreen ds DNA reagent (Molecular Probes).

Samples were thus mixed to contain a 100-fold and a 1000-fold excess of target rDNAs (krill 28SrDNA) compared with nontarget rDNAs (Pyramimonas sp.). A sample containing only krill DNA was used as a control.

Amplification with blocking primers were performed as $25 \mu \mathrm{L}$ reactions with $0.25 \mu \mathrm{L}$ of each of the universal $28 \mathrm{~S}$ rDNA primers Short $28 \mathrm{SF}(10 \mu \mathrm{M})$ and Short $28 \mathrm{SR}(10 \mu \mathrm{M})$,

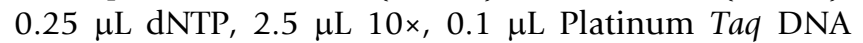
Polymerase High Fidelity (Invitrogen) $5 \mathrm{U} \cdot \mu \mathrm{L}^{-1}, 1 \mu \mathrm{L} \mathrm{Mg}^{2+}$ and a variable amount of blocking primer and rDNA. PCR thermal cycling conditions were: $2 \mathrm{~min}$ at $94^{\circ} \mathrm{C} ; 40$ cycles of $10 \mathrm{~s}$ at $94^{\circ} \mathrm{C}, 30 \mathrm{~s}$ at $59^{\circ} \mathrm{C}, 30 \mathrm{~s}$ at $68^{\circ} \mathrm{C}$; and finally 5 $\min$ at $72^{\circ} \mathrm{C}$.

Blocking efficiency was assessed by fragment analysis of the fluorescently labelled PCR products. Fragment analysis separates a mixture of DNA fragments according to their sizes and is much more sensitive than standard gel electrophoresis. The analysis was performed on an Applied Biosystems $3130 \mathrm{xl}$ Capillary Electrophoresis (CE) Genetic Analyser and results were analyzed with Peak Scanner Software 1.0 (Applied Biosystems).

\section{PCR amplification of prey DNA from krill stomachs}

After determining the most efficient blocking primer mixture, PCR was performed on krill stomach isolates. PCRs were prepared using UV sterilized equipment and consumables and negative (no-template) controls were always run alongside the samples. The PCR reactions were carried out on a MJ Research DNA engine Gradient Cycler (eq. Chromo 4) and sequencing was performed on a 3730 xl DNA analyzer (Applied Biosystems). PCR products were checked by electrophoresis on a $1.3 \%$ agarose gel stained with SYBR ${ }^{\circledR}$ Safe DNA gel stain (Invitrogen). Visible bands were cut out and purified with Bio-Rad Quantum Prep Freeze'N Squeeze DNA Gel Extraction Spin Columns.

The PCR products were thereafter reincubated for $10 \mathrm{~min}$ at $72^{\circ} \mathrm{C}$ with $20 \mu \mathrm{L}$ reaction volume containing $2 \mu \mathrm{L} 10 \times$, $1 \mu \mathrm{L} \mathrm{Mg}{ }^{2+}, 0.2 \mu \mathrm{L}$ Biotaq TM DNA Polymerase (Bioline) and $0.2 \mu \mathrm{L}$ dNTP to add 3 ' adenines and cloned using the TOPO TA Cloning system competent cells (Invitrogen). Transformants were picked for PCR and amplification was performed with the TOPO_F and TOPO_R primers as 25 $\mu \mathrm{L}$ reactions with $0.25 \mu \mathrm{L}$ of each oligo $(10 \mu \mathrm{M}), 0.25 \mu \mathrm{L}$

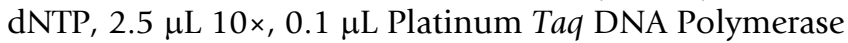
High Fidelity (Invitrogen) $5 \mathrm{U} \cdot \mu \mathrm{L}^{-1}$ and $1 \mu \mathrm{L} \mathrm{Mg}^{2+}$. PCR thermal cycling conditions were: 2 min at $94^{\circ} \mathrm{C} ; 40$ cycles of $10 \mathrm{~s}$ at $94^{\circ} \mathrm{C}, 30 \mathrm{~s}$ at $65^{\circ} \mathrm{C}, 30 \mathrm{~s}$ at $68^{\circ} \mathrm{C}$; and finally 5 $\min$ at $72^{\circ} \mathrm{C}$.

Sequences were generated from these PCR products with the M13 forward primer and BigDye Terminator v3.1 sequencing reactions $(\mathrm{ABI})$.

Amplification for sequencing of species not yet available in GenBank were performed as $25 \mu \mathrm{L}$ reactions with 0.25 $\mu \mathrm{L}$ of each of the universal $28 \mathrm{~S}$ rDNA primers Short28SseqF and Short28SseqR (10 $\mu \mathrm{M})$ (Table 1) designed to cover a larger area than the Short28SF/ Short28SR primers, including their primer binding sites,

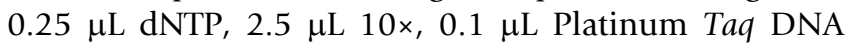
Polymerase High Fidelity (Invitrogen) $5 \mathrm{U} \cdot \mu \mathrm{L}^{-1}$ and $1 \mu \mathrm{L}$ $\mathrm{Mg}^{2+}$. PCR thermal cycling conditions were unmodified except for increasing the elongation step to $60 \mathrm{~s}$.

\section{Clone identification}

Clones were tentatively identified by finding their closest match in the GenBank database using the BLASTN algorithm [43]. All the sequences (clones and closest matches) were then aligned in MEGA 4 [44] and a similarity tree was created using Tamura-Nei distances [45] and the minimum evolution algorithm with gap handling by pairwise deletion. 


\section{Results}

\section{Blocking primer performance}

Adding a blocking primer to the PCR mixture clearly decreased the number of predator fragments amplified and enriched the number of rarer prey fragments. In rDNA mixtures containing 1000 times as many "predator" (krill) rDNA fragments compared to "prey" (algae) rDNA fragments, only peaks corresponding to krill rDNA could be detected by fragment analysis when no blocking primer was added (Table 3). Adding an annealing inhibiting blocking primer in a ratio $4: 1$ compared to the corresponding universal primer $(1.0 \mu \mathrm{L}$ blocking primer and $0.25 \mu \mathrm{L}$ universal primer, both $10 \mu \mathrm{M}$ ) led to reduced amplification of krill rDNAs but not to complete amplification arrest (Table 3). And by adding 10 times as much blocking primer as universal primers $(2.5 \mu \mathrm{L}$ blocking primer and $0.25 \mu \mathrm{L}$ each universal primer), algal rDNA was almost exclusively amplified (Table 3). Adding 20 times as much blocking primer $(5.0 \mu \mathrm{L}$ blocking primer and $0.25 \mu \mathrm{L}$ each universal primer) decreased the krill peak even further (Table 3 ).

The "normal" primer Short28SR-blkKrill3'c3 seemed to be somewhat more efficient in blocking predator DNA compared to the DPO primer Short28SF-DPO-blkKrill. Peaks corresponding to krill rDNA were lower in the $4: 1$ blocking primer: universal primer mixtures for both the 1:100 and the 1:1000 prey: predator rDNA samples with the normal primer compared to the mixtures with the DPO primer (Table 3 ). However, the DPO primer largely blocked krill DNA amplification when added in a ratio of 10:1 to the unmodified primer (Table 3).

The elongation arrest primer 28S-ElArKrill-3'c3 did not work. No PCR product at all was generated when it was added to the PCR mixture (data not shown).

\section{Krill stomach analysis}

In total 111 clones from 13 different krill stomachs were sequenced revealing 36 different sequences falling into 6 major groups. Among them there were no sequences corresponding to the wild type of krill 28s rDNA. 10 different (15 in total) sequences were however clearly of krill origin (Figure 3) and probably pseudogenes or low copy versions normally not detected by direct sequencing.

Four different groups of algal sequences were found. Two of these groups, only detected in the March samples, had their closest match to species belonging to Bacillariophyta, respectively the genus Phaeodactylum and the genus Skeletonema (Figure 3). A third group, found in stomachs from all three sampling dates seemed to be somewhat

Table 3: Results from fragment analysis showing the algae and krill peak height generated from PCR mixtures with different amounts of the different blocking primers added and different initial concentration of algal 28S rDNA fragments.

\begin{tabular}{|c|c|c|c|c|}
\hline \multirow{2}{*}{$\begin{array}{l}\text { Initial concentration } \\
\text { of Pyramimonas fragments to } \\
\text { Euphausia fragments }\end{array}$} & \multirow[t]{2}{*}{ Blocking primer } & \multirow{2}{*}{$\begin{array}{l}\text { Amount of } 10 \mu \mathrm{M} \\
\text { blocking primer added }\end{array}$} & \multicolumn{2}{|l|}{ Peak height } \\
\hline & & & $\begin{array}{l}\text { Fragment length } 180 \\
\text { (Pyramimonas sp.) }\end{array}$ & $\begin{array}{l}\text { Fragment length } 199 \\
\text { (Euphausia superba) }\end{array}$ \\
\hline \multirow[t]{7}{*}{$1: 100$} & No blocking & $0 \mu \mathrm{L}$ & 311 & 8107 \\
\hline & Short28SR- & $1.0 \mu \mathrm{L}$ & 8454 & 3030 \\
\hline & & $2.5 \mu \mathrm{L}$ & 8516 & 186 \\
\hline & blkKrill-3'c3 & $5.0 \mu \mathrm{L}$ & 8243 & 0 \\
\hline & Short28SF- & $\mathrm{I} .0 \mu \mathrm{L}$ & 8374 & 7538 \\
\hline & & $2.5 \mu \mathrm{L}$ & 8524 & 190 \\
\hline & DPO-blkKrill & $5.0 \mu \mathrm{L}$ & 8498 & 66 \\
\hline \multirow[t]{7}{*}{$1: 1000$} & No blocking & $0 \mu \mathrm{L}$ & 0 & 8301 \\
\hline & Short28SR- & $\mathrm{I} .0 \mu \mathrm{L}$ & 8480 & 6025 \\
\hline & & $2.5 \mu \mathrm{L}$ & 8470 & 146 \\
\hline & blkKrill-3'c3 & $5.0 \mu \mathrm{L}$ & 8617 & 0 \\
\hline & Short28SF- & I.0 $\mu \mathrm{L}$ & 7740 & 8309 \\
\hline & & $2.5 \mu \mathrm{L}$ & 8427 & 318 \\
\hline & DPO-blkKrill & $5.0 \mu \mathrm{L}$ & 8427 & 140 \\
\hline Krill only & No blocking & $0 \mu \mathrm{L}$ & 0 & 8324 \\
\hline
\end{tabular}




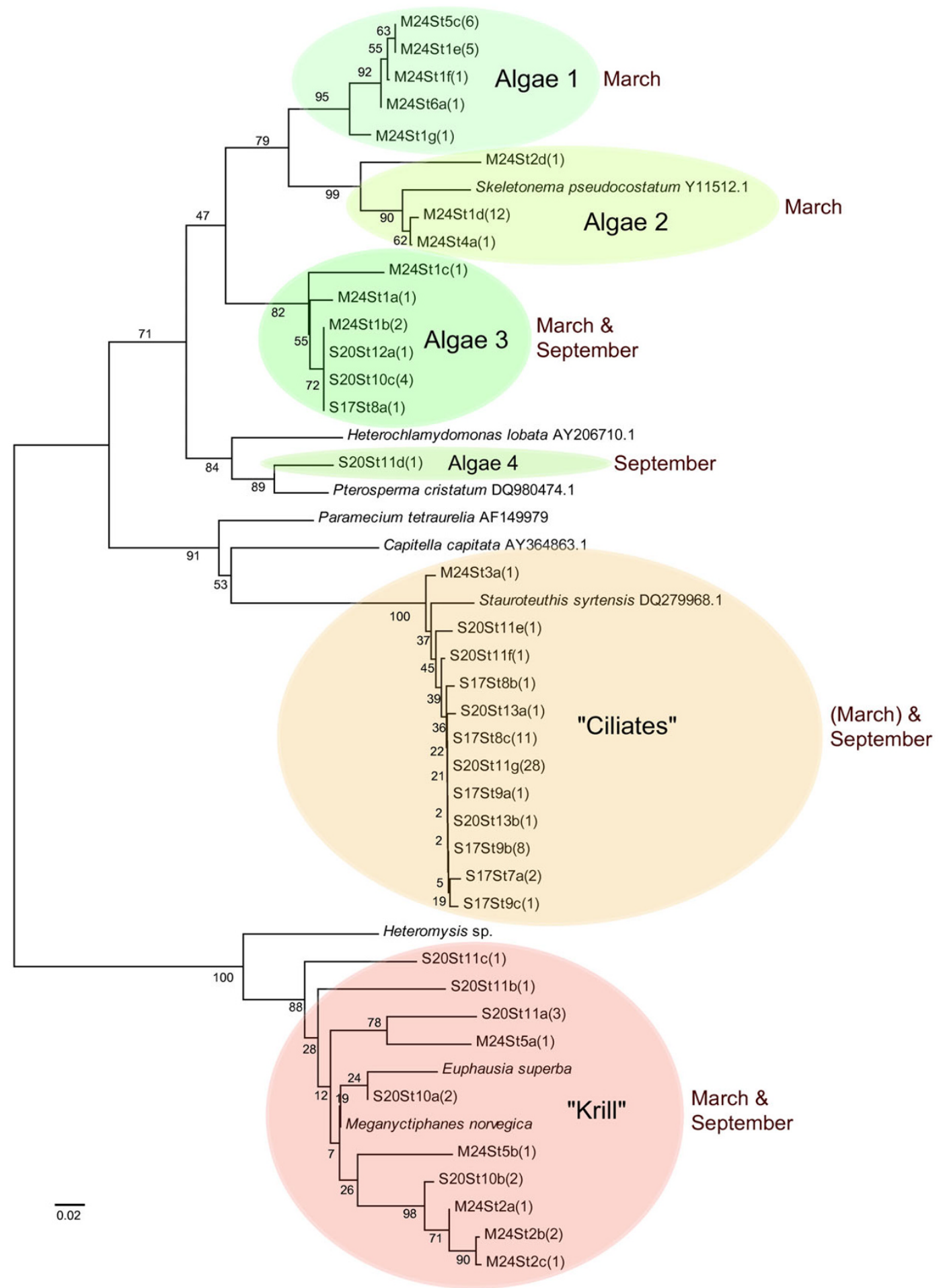

\section{Figure 3}

Sequence similarity tree. Sequence similarity tree of sequences amplified from krill stomachs and related sequences. The krill stomach sequences are named so as the first three letters means sampling date, i.e. M24 = March 24. 2007, S17 and S20 = September 17. and September 20. 2007, St. means Stomach number and the number in parenthesis equals the number of identical sequences of each different sequence found in the different stomachs. The tree is unrooted. 
similar to the Bacillariophyta, but did not match anything in GenBank (Figure 3). The 200 bp area sequenced was too uninformative to reveal where the group belonged by phylogentic analysis, besides that the group most likely was of algal origin. The last algal group was one sequence from September belonging to Chlorophyta (Figure 3).

One large group of sequences, which was prevalent in the September sample, could not be unequivocally identified by reference to current sequences in GenBank. The closest matches was a 96\% match to Stauroteuthis (Mollusca). It is possible that this may represent mollusc food items such as larval squid. However, it is also possible that the Stauroteuthis sequence has been misreported and is actually derived from a contaminant of the original Stauroteuthis sample.

The sequences have been deposited to GenBank under the accession numbers EU378965 - EU379000.

\section{Discussion}

This study shows that complete removal of predator sequences could be achieved by adding a predator specific blocking primer to a PCR mixture. Even though more sophisticated sequencing techniques such as pyrosequencing [46] and polony sequencing [47] now open new possibilities in assessing sequence diversity of mixed templates [48], applying a method that screens away templates assumed to occur in 1000-fold excess compared to what you are looking for will certainly be beneficial. Adding a predator specific blocking primer is also a simple method that allows for using a single PCR to simultaneously amplify DNA from all prey items present in each stomach sample. Furthermore, it does not depend on tests being developed a priori for potential prey, the only sequence that is needed to be known, is the sequence of the predator itself.

In this study we also show that a DPO primer [41] having the 3 ' end blocked also could be used as a blocking primer. This extends the region to look for species-specific blocking sites and is very useful especially since initial trials with a krill specific 'elongation arrest' primer located between the forward and reverse universal primer did not work.

It is not known why the elongation arrest primer was unsuccessful. Von Wintzingerode et al. [31] and also Peano et al. [33] using PCR clamping and PNA probes found that elongation arrest clamping worked, but that competitive clamping (annealing inhibition) was more efficient, and the former hypothesised that this was due to interaction between the Taq polymerase and PNA and DNA. However, since elongation arrest primers allows the unmodified version of the universal primer to bind to the dominating sequence, and just inhibit the generating of its amplicons, perhaps the explanation of no PCR product is that the universal primers never found the rarer sequences. It is also a possibility that the 'blocking primer' of Lewis et al. [42] is simply producing a more efficient PCR reaction with a shorter product, rather than truly 'blocking' the amplification of the longer product.

Blocking primer performance was sensitive to the amount of blocking primer added. We found that a 10 fold molar excess was sufficient for complete blocking to the detection limit of our assay, when the dominant template occurred in 1000 fold excess of the minor template. It is difficult to compare primer concentrations between blocking primer studies since concentration of the unmodified primers and DNA templates also tends to vary (like e.g. vs. reference [34]). The blocking primer in our study was designed to be species specific. However, it could block other species as well, something that cannot be excluded without extensive empirical testing. Keeping blocking primer concentration at the minimum required amount is probably a good rule of thumb.

We only identified algal sequences in the krill stomachs besides krill pseudogenes/low copy genes and an anonymous phylotype. Complete sequence coverage of all the potential krill prey was not available and it was naturally not possible to test experimentally if the blocking primers designed to be krill specific also blocked any other organisms beside krill. However, since krill obviously could and did feed on algae at both occasions, the DNA types detected were probably representative snapshots of krill diet at the three different sampling times.

Krill caught in September differed from krill caught in March in that sequences belonging to Bacillariophyta (diatoms) only were detected in the March samples. Further, a sequence belonging to Chlorophyta was only found in krill caught in September. The unidentified algal group, found in stomachs from all three sampling dates seemed to be related to diatoms, even though it is difficult to determine based on a 200 bp fragment. Many known Antarctic algal groups, including the frequently dominant group Parmales that is morphologically similar to diatoms [49], are not yet represented in sequence databases because they are so difficult to culture. Our unidentified algal group could belong to Parmales, or be something else. We also found another unknown phylotype. Finding rDNA that does not match any known sequences is common in molecular studies of eukaryotic diversity [e.g. $[19,50]]$. But as barcoding initiatives results in more and more available sequence data, especially if they could include also other DNA regions beside mtCOI, this will be less of a problem in the future. 
The identification of several krill pseudogenes or low copy genes is interesting. Different strategies are being developed in analyzing functional RNA genes [51]. Indicators of pseudo-rDNA genes might for example be elevated levels of uncompensated base changes within stem regions (see e.g. [52]). We did not perform secondary structure predictions for the 'krill-like' sequences, and cannot tell whether they are pseudogenes or expressed and functional low-copy versions. 28S rDNA is expected to be very homogenized by molecular drive [53], but there are also reports of distinct rDNA classes within species [52,54]. Whatever is the case with the sequences detected here, the results demonstrate that by blocking dominant sequences from amplification, interesting variation is revealed that might remain undetected by conventional PCR-cloning assays.

\section{Conclusion}

DNA based techniques are valuable in tracking predatorprey interactions because they do not rely on the presence of visually diagnostic remains. In this study we have demonstrated how blocking primers can be used to filter out the dominating DNA from the predator itself, allowing detection of food derived DNA fragments by the use of universal PCR primers.

\section{Competing interests}

The authors declare that they have no competing interests.

\section{Authors' contributions}

HV carried out most of the laboratory work and data analysis and drafted the manuscript. SNJ designed the study and did some of the preliminary laboratory work. Both authors participated in the development of concepts presented in the paper and contributed significantly to the writing of the final version of the manuscript. Both authors read and approved the final manuscript.

\section{Acknowledgements}

We thank S. Kawaguchi for collecting krill and zooplankton, J. Kitchener for help with species identification and B. Deagle for constructive comments.

\section{References}

I. Loeb V, Siegel V, HolmHansen O, Hewitt R, Fraser W, Trivelpiece W, Trivelpiece S: Effects of sea-ice extent and krill or salp dominance on the Antarctic food web. Nature 1997, 387(6636):897-900.

2. Heywood BG, Brierley AS, Gull SF: A quantified Bayesian maximum entropy estimate of Antarctic krill abundance across the Scotia Sea and in small-scale management units from the CCAMLR-2000 survey. CCAMLR Science 2006, 13:97-I |6.

3. Croxall JP, Nicol S: Management of Southern Ocean fisheries: global forces and future sustainability. Antarctic Science 2004, 16(4):569-584.

4. Marr JSW: Discovery report. 1962, 32(33):

5. Schmidt K, Atkinson A, Petzke KJ, Voss M, Pond DW: Protozoans as a food source for Antarctic krill, Euphausia superba: Complementary insights from stomach content, fatty acids, and stable isotopes. Limnology and Oceanography 2006, 5 I (5):2409-2427.
6. Ikeda $\mathrm{T}$, Dixon P: Body shrinkage as a possible over-wintering mechanism of the Antarctic krill, Euphausia superba Dana. Journal of Experimental Marine Biology and Ecology 1982, 62(2): I43-I5I.

7. Nicol S, Stolp M, Cochran T, Geijsel P, Marshall J: Growth and shrinkage of Antarctic krill Euphausia superba from the Indian Ocean sector of the Southern Ocean during summer. Marine Ecology-Progress Series 1992, 89(2-3): 175-181.

8. Kawaguchi K, Matsuda O, Ishikawa S, Naito Y: A light trap to collect krill and other micronektonic and planktonic animals under the Antarctic coastal fast ice. Polar Biology 1986, 6(I):37-42.

9. Quetin LB, Ross RM: Behavioral and physiological characteristics of the Antarctic krill, Euphausia superba. American Zoologist |991, 3 I(I):49-63.

10. Lancraft TM, Hopkins TL, Torres JJ, Donnelly J: Oceanic micronektonic macrozooplanktonic community structure and feeding in ice covered Antarctic waters during the winter (ameriez 1988). Polar Biology I99I, I I(3):I57-167.

II. Stretch JJ, Hamner PP, Hamner WM, Michel WC, Cook J, Sullivan CW: Foraging behavior of Antarctic krill Euphausia superba on sea ice microalgae. Marine Ecology-Progress Series 1988, 44(2): $131-139$.

12. King RA, Read DS, Traugott M, Symondson WOC: Molecular analysis of predation: a review of best practice for DNA-based approaches. Molecular Ecology 2008, I 7(4):947-963.

13. Symondson WOC: Molecular identification of prey in predator diets. Molecular Ecology 2002, I I (4):627-64I.

14. Polz MF, Cavanaugh CM: Bias in template-to-product ratios in multitemplate PCR. Appl Environ Microbiol 1998, 64(10):3724-3730.

15. Green SJ, Minz D: Suicide polymerase endonuclease restriction, a novel technique for enhancing PCR amplification of minor DNA templates. Applied and Environmental Microbiology 2005, 7 I (8):472I-4727.

16. Nejstgaard JC, Frischer ME, Simonelli P, Troedsson C, Brakel M, Adiyaman F, Sazhin AF, Artigas LF: Quantitative PCR to estimate copepod feeding. Marine Biology 2008, I53(4):565-577.

17. Deagle BE, Eveson JP, Jarman SN: Quantification of damage in DNA recovered from highly degraded samples - a case study on DNA in faeces. Front Zool 2006, Aug 16:3-11.

18. Deagle BE, Tollit DJ, Jarman SN, Hindell MA, Trites AW, Gales NJ: Molecular scatology as a tool to study diet: analysis of prey DNA in scats from captive Steller sea lions. Molecular Ecology 2005, I 4(6): I83I-1842.

19. Jarman SN, Deagle BE, Gales NJ: Group-specific polymerase chain reaction for DNA-based analysis of species diversity and identity in dietary samples. Molecular Ecology 2004, 13(5): | $313-1322$.

20. Blankenship LE, Levin LA: Extreme food webs: Foraging strategies and diets of scavenging amphipods from the ocean's deepest 5 kilometers. Limnology and Oceanography 2007, 52(4): 1685-1697.

21. Blankenship LE, Yayanos AA: Universal primers and PCR of gut contents to study marine invertebrate diets. Molecular Ecology 2005, I 4(3):89|-899.

22. Agusti N, Shayler SP, Harwood JD, Vaughan IP, Sunderland KD, Symondson WOC: Collembola as alternative prey sustaining spiders in arable ecosystems: prey detection within predators using molecular markers. Molecular Ecology 2003, I 2( I 2):3467-3475.

23. Nejstgaard JC, Frischer ME, Raule CL, Gruebel R, Kohlberg KE, Verity PG: Molecular detection of algal prey in copepod guts and fecal pellets. Limnology and Oceanography: Methods 2003, 1:29-38.

24. Vestheim H, Edvardsen B, Kaartvedt S: Assessing feeding of a carnivorous copepod using species-specific PCR. Marine Biology 2005, I 47(2):38I-385.

25. Jarman SN, Redd KS, Gales NJ: Group-specific primers for amplifying DNA sequences that identify Amphipoda, Cephalopoda, Echinodermata, Gastropoda, Isopoda, Ostracoda and Thoracica. Molecular Ecology Notes 2006, 6(I):268-27I.

26. Passmore AJ, Jarman SN, Swadling KM, Kawaguchi S, McMinn A, Nicol S: DNA as a dietary biomarker in Antarctic krill, Euphausia superba. Marine Biotechnology 2006, 8(6):686-696.

27. Karkare $S$, Bhatnagar D: Promising nucleic acid analogs and mimics: characteristic features and applications of PNA, 
LNA, and morpholino. Applied Microbiology and Biotechnology 2006, 7 I(5):575-586.

28. Egholm M, Buchardt O, Christensen L, Behrens C, Freier SM, Driver DA, Berg RH, Kim SK, Norden B, Nielsen PE: PNA hybridizes to complementary oligonucleotides obeying the Watson-Crick hydrogen-bonding rules. Nature 1993, 365(6446):566-568.

29. Ørum H, Nielsen PE, Egholm M, Berg RH, Buchardt O, Stanley C: Single-base pair mutation analysis by PNA directed PCR clamping. Nucleic Acids Research 1993, 2 I (23):5332-5336.

30. Hancock DK, Schwarz FP, Song FH, Wong LJC, Levin BC: Design and use of a peptide nucleic acid for detection of the heteroplasmic low-frequency mitochondrial encephalomyopathy, lactic acidosis, and stroke-like episodes (MELAS) mutation in human mitochondrial DNA. Clinical Chemistry 2002, 48(I 2):2| $155-2 \mid 63$.

31. von Wintzingerode F, Gobel UB, Stackebrandt E: Determination of microbial diversity in environmental samples: pitfalls of PCR-based rRNA analysis. Fems Microbiology Reviews 1997, 2I(3):2I3-229.

32. Troedsson C, Lee RF, Walters T, Stokes V, Brinkley K, Naegele V, Frischer ME: Detection and discovery of crustacean parasites in blue crabs (Callinectes sapidus) by I8S rDNA targeted denaturing high-performance liquid chromatography (DHPLC). Appl Environ Microbiol 2008:AEM.02I32-7.

33. Peano C, Lesignoli F, Gulli M, Corradini R, Samson MC, Marchelli R, Marmiroli N: Development of a peptide nucleic acid polymerase chain reaction clamping assay for semiquantitative evaluation of genetically modified organism content in food. Analytical Biochemistry 2005, 344(2): I74- 82.

34. Khanna M, Park P, Zirvi M, Cao WG, Picon A, Day J, Paty P, Barany F: Multiplex PCR/LDR for detection of K-ras mutations in primary colon tumors. Oncogene 1999, 18(I):27-38.

35. Liles MR, Manske BF, Bintrim SB, Handelsman J, Goodman RM: A census of rRNA genes and linked genomic sequences within a soil metagenomic library. Applied and Environmental Microbiology 2003, 69(5):2684-2691.

36. Zaidi RH, Jaal Z, Hawkes NJ, Hemingway J, Symondson WOC: Can multiple-copy sequences of prey DNA be detected amongst the gut contents of invertebrate predators? Molecular Ecology I 999, 8( I 2):208|-2087.

37. Woese CR: Bacterial evolution. Microbiological Reviews 1987, 5 I (2):22I-27I.

38. Dames S, Margraf RL, Pattison DC, Wittwer CT, Voelkerding KV: Characterization of aberrant melting peaks in unlabeled probe assays. Journal of Molecular Diagnostics 2007, 9(3):290-296.

39. Cradic KW, Wells JE, Allen L, Kruekeberg KE, Singh RJ, Grebe SKG: Substitution of 3'-phosphate cap with a carbon-based blocker reduces the possibility of fluorescence resonance energy transfer probe failure in real-time PCR assays. Clinical Chemistry 2004, 50(6): 1080-1082.

40. Wu DY, Ugozzoli L, Pal BK, Qian J, Wallace RB: The effect of temperature and oligonucleotide primer length on the specificity and efficiency of amplification by the polymerase chainreaction. DNA Cell Biol I99I, 10(3):233-238.

41. Chun JY, Kim KJ, Hwang IT, Kim YJ, Lee DH, Lee IK, Kim JK: Dual priming oligonucleotide system for the multiplex detection of respiratory viruses and SNP genotyping of CYP2CI9 gene. Nucleic Acids Research 2007, 35(6):.

42. Lewis AP, Sims MJ, Gewert DR, Peakman TC, Spence H, Crowe JS: Taq DNA-polymerase extension of internal primers blocks polymerase chain-reactions allowing differential amplification of molecules with identical 5 '-end and 3'-end. Nucleic Acids Research 1994, 22(14):2859-286I.

43. Altschul SF, Madden TL, Schaffer AA, Zhang JH, Zhang Z, Miller W, Lipman DJ: Gapped BLAST and PSI-BLAST: a new generation of protein database search programs. Nucleic Acids Research 1997, 25(I 7):3389-3402.

44. Tamura K, Dudley J, Nei M, Kumar S: MEGA4: Molecular evolutionary genetics analysis (MEGA) software version 4.0. Molecular Biology and Evolution 2007, 24(8): I596-1599.

45. Tamura K, Nei M: Estimation of the number of nucleotide substitutions in the control region of mitochondrial DNA in humans and chimpanzees. Mol Biol Evol 1993, 10(3):5I2-526.

46. Margulies M, Egholm M, Altman WE, Attiya S, Bader JS, Bemben LA, Berka J, Braverman MS, Chen YJ, Chen ZT, Dewell SB, Du L, Fierro JM, Gomes XV, Godwin BC, He W, Helgesen S, Ho CH, Irzyk GP,
Jando SC, Alenquer MLI, Jarvie TP, Jirage KB, Kim JB, Knight JR, Lanza JR, Leamon JH, Lefkowitz SM, Lei M, Li J, Lohman KL, Lu H, Makhijani VB, McDade KE, McKenna MP, Myers EW, Nickerson E, Nobile JR, Plant R, Puc BP, Ronan MT, Roth GT, Sarkis G], Simons JF, Simpson JW, Srinivasan M, Tartaro KR, Tomasz A, Vogt KA, Volkmer GA, Wang SH, Wang Y, Weiner MP, Yu PG, Begley RF, Rothberg JM: Genome sequencing in microfabricated high-density picolitre reactors. Nature 2005, 437(7057):376-380.

47. Shendure J, Porreca G], Reppas NB, Lin XX, McCutcheon JP, Rosenbaum AM, Wang MD, Zhang K, Mitra RD, Church GM: Accurate multiplex polony sequencing of an evolved bacterial genome. Science 2005, 309(574I): 1728-I732.

48. Hall N: Advanced sequencing technologies and their wider impact in microbiology. Journal of Experimental Biology 2007, 210(9): $15 \mid 8-1525$

49. Scott FJ, Marchant HJ: Antarctic marine protists. Hobart/Canberra, ABRS/AAD; 2005:579.

50. Baldauf SL: The deep roots of eukaryotes. Science 2003 300(5626): 1703-1706.

5I. Machado-Lima A, del Portillo HA, Durham AM: Computational methods in noncoding RNA research. Journal of Mathematical Biology 2008, 56(I-2): 15-49.

52. Telford MJ, Holland PWH: Evolution of 285 ribosomal DNA in chaetognaths: Duplicate genes and molecular phylogeny. Journal of Molecular Evolution 1997, 44(2): I 35- I 44.

53. Dover GA: Molecular drive in multigene families - How biological novelties arise, spread and are assimilated. Trends in Genetics 1986, 2(6): 159-165.

54. Hui JHL, Kortchagina N, Arendt D, Balavoine G, Ferrier DEK: Duplication of the ribosomal gene cluster in the marine polychaete Platynereis dumerilii correlates with ITS polymorphism. Journal of The Marine Biological Association of The United Kingdom 2007, 87(2):443-449.
Publish with BioMed Central and every scientist can read your work free of charge

"BioMed Central will be the most significant development for disseminating the results of biomedical research in our lifetime. "

Sir Paul Nurse, Cancer Research UK

Your research papers will be:

- available free of charge to the entire biomedical community

- peer reviewed and published immediately upon acceptance

- cited in PubMed and archived on PubMed Central

- yours - you keep the copyright

Submit your manuscript here:

http://www.biomedcentral.com/info/publishing_adv.asp
BioMedcentral 